\title{
A Double-Blind Comparative Study between Generic Sevoflurane and Sevorane ${ }^{\mathrm{TM}}$
}

\author{
Alfredo Augusto Vieira Portella, TSA ${ }^{1}$, Solange Maria Laurencel, TSA 2, Deise Martins Rosa, TSA 2, \\ Maria Isabel Moscote Rivera ${ }^{3}$, Santiago Osorno Quintero ${ }^{4}$
}

Summary: Portella AAV, Laurencel SM, Rosa DM, Rivera MIM, Quintero SO - A Double-Blind Comparative Study between Generic Sevoflurane and Sevorane ${ }^{\mathrm{TM}}$

Background and objectives: Sevoflurane is presented in three types of vials. The differences in physical-chemical properties of those products are due to different manufacturing processes, although they are essentially identical regarding chemical comparison tests. It has been hypothesized that the Sevoflurane molecule could present chemical instability due to the formation of Lewis acids as a consequence of the materials used in the fabrication of the vials and the water content. The objective of this study was to analyze the clinical efficacy of Sevoflurane conditioned in different vials.

Methods: Sixty-four adult patients were randomly divided into two groups. Two Datex-Ohmeda vaporizers, one with only Generic Sevoflurane and the other with Sevorane ${ }^{\mathrm{TM}}$, were used. The study coordinator was responsible for supplying the vaporizers and he did not participated in none anesthetic procedures. The same anesthetic technique and monitoring (ECG, HR, $\mathrm{SpO}_{2}, \mathrm{P}_{\mathrm{ET}} \mathrm{CO}_{2}, \mathrm{BIS}, \mathrm{SEF}$, TOF, \% INSP, \% EXP, SBP, and DBP) were used in both groups.

Results: During anesthesia, differences were not observed between both groups. A statistically significant difference was observed in the time between the interruption of Sevoflurane and spontaneous eye opening (13,91 \pm 6.39 min in Group II, and $10.34 \pm 6.05$ min in Group I) and the interruption of Sevoflurane and handgrip on verbal command (15.38 $\pm 6.47 \mathrm{~min}$ in Group II, and $11.88 \pm 6.60$ in Group I). A statistically significance difference was not observed between the interruption of Sevoflurane and the moment that patients achieved an AldreteKroulik index equal or above 8.

Conclusions: during anesthesia a significant difference between both groups was not observed. Although awakening was 3,5 minutes faster in Group I (Generic Sevoflurane), anesthesiologists did not observe any difference in the clinical behavior of patients.

Keywords: ANESTHESICS, Volatile: sevoflurane.

Financial support: Instituto BioChimico Indústria Farmacêutica Ltda. Rodovia Pres. Dutra, km 310 - Itatiaia - RJ. Zip code $27580-000$.

\section{INRODUCTION}

In 1990, the Maruishi Pharmaceutical Company (Japan) obtained registration for the commercialization and clinical use of sevoflurane, initially in Japan. In 1992, Abbott Laboratory obtained the license and in 1995 it was commercialized in the United States.

Abbott sevoflurane is manufactured by Central Glass in Japan, and distributed all over the world, being commercialized in the United States under the name Ultane ${ }^{\mathrm{TM}}$ and in Latin America under the name Sevorane ${ }^{\mathrm{TM}}$.

Received from Hospital Universitário Pedro Ernesto, UERJ.

1. Professor, Chief of the Anesthesiology Department of Hospital Universitário Pedro Ernesto

2. Anesthesiologist of Hospital Universitário Pedro Ernesto - UERJ, Co-responsible for the CET/SBA of Hospital Universitário Pedro Ernesto - UERJ

3. Physician, R3 in Anesthesiology of the Programa de Especialidade Médica para Estrangeiros do Hospital Universitário Pedro Ernesto - UERJ

4. Physician, R2 in Anesthesiology of the Programa de Especialidade Médica para Estrangeiros do Hospital Universitário Pedro Ernesto - UERJ

Submitted on February 2, 2010.

Approved on May 10, 2010.

Correspondence to:

Dr. Alfredo Augusto V. Portella

Rua Almirante Tamandaré, 53/402

Flamengo

CEP: 22210-060 - Rio de Janeiro, RJ, Brazil

E-mail: aportella@openlink.com.br
Sevoflurane used in Latin America, including Brazil, is commercialized by three pharmaceutical industries (Abbott, Cristália, and BioChimico), and its use is authorized by national supervising and regulatory organs.

After launched by Abbott, two other products were licensed and commercialized in Brazil: the first one in 2002, by Laboratório Cristália (Sevocris ${ }^{\mathrm{TM}}$ ); the second in 2007 by Instituto Biochimico as a generic drug. Baxter laboratory also commercializes sevoflurane; however, this product is not available in Brazil.

Sevoflurane is conditioned in three different vials and uses water (in different concentrations) or propylene glycol as stabilizer:

1. Abbott (Sevorane ${ }^{\mathrm{TM}}$, Ultane $^{\mathrm{TM}}$ ): conditioned in plastic vials of polyethylene naphthtalate (PEN) containing a high water content (at least 300 ppm).

2. BioChimico (Generic Sevoflurane): conditioned in amber glass vials USP type III containing low water content (65 ppm).

3. Cristália (Sevocris ${ }^{\mathrm{TM}}$ ): conditioned in amber glass vials USP type III containing $0.026 \%$ of propylene glycol.

4. Baxter (Svofast ${ }^{\mathrm{TM}}$, not available in Brazil): conditioned in epoxy phenol-coated aluminum vials containing medium water content (130 ppm). 
When the physical-chemical properties of those products are analyzed, subtle differences can be identified especially regarding type and content of impurities, which are due to the different manufacture processes used. However, chemical comparison testing demonstrates that the products are essentially identical.

Currently, there is an intense disagreement involving the hypothesis that the sevoflurane molecule could present chemical instability due to the formation of Lewis acids, which would be a consequence of the characteristics of the vials used and water content of its compositions. In order to prove of rebut the presence of this instability several studies have been published ${ }^{1-7}$.

Although this controversy has not been fully cleared, another question has risen: could the type of vial used to carry sevoflurane alter it pharmacological properties and consequently interfere with its clinical effects?

In an attempt to find the answer to this question, the present clinical study was designed to analyze the clinical efficacy of sevoflurane conditioned in different vials and with different water contents as seen with Generic Sevoflurane (BioChimico) and Sevorane ${ }^{\mathrm{TM}}$ (Abbott).

\section{METHODS}

After approval by the Ethics on Research Commission of the Hospital Universitário Pedro Ernesto of the Universidade do Estado do Rio de Janeiro, 64 adult patients of both genders, physical status ASA I or II, scheduled for elective surgeries under general anesthesia were randomly divided into two groups.

All patients signed a standardized informed consent at the Hospital Universitário Pedro Ernesto da Universidade do Estado do Rio de Janeiro where the study was undertaken.

The statistician considered the number of patients enough for analysis of the data presented.

Two Datex-Ohmeda vaporizers that had never been used calibrated for Sevoflurane were set up for this study, one of them to be used only for Generic Sevoflurane (vaporizer \#I) and the other only with Sevorane ${ }^{\mathrm{TM}}$ (vaporizer \#II).

During the study the anesthesiologists who were responsible for anesthesia were unaware of the origin of the sevoflurane in the vaporizers. The study coordinator was the only one responsible for supplying the vaporizers and he was not in charge of any anesthesia. Only after the conclusion of the cases it was revealed which sevoflurane was used in each vaporizer.

Patients were pre-medicated with $7.5 \mathrm{mg}$ of oral midazolam 60 minutes before anesthetic induction. In the operating room, after venipuncture of a peripheral vein in the upper limb, sedation was complemented if necessary with $1 \mathrm{mg}$ of midazolam IV every 2 minutes until the patient fell asleep, but could be easily awaken by small sound or tactile stimuli (Ramsay 3 - BIS 75 to 80).

During the study the following parameters were monitored continuously: cardiac electric activity (ECG), heart rate (HR), peripheral oxygen saturation $\left(\mathrm{SpO}_{2}\right)$, expired fraction of $\mathrm{CO}_{2}$ $\left(\mathrm{P}_{\mathrm{ET}} \mathrm{CO}_{2}\right)$, bispectral index (BIS), spectral edge frequency (SEF), intensity of the neuromuscular blockade (TOF), and the inspired (\% INSP) and expired (\% EXP) concentrations of sevoflurane. Intermittently, non-invasive systolic (SBP) and diastolic (DBP) were also recorded.

Anesthesia was induced with the intravenous administration of $40 \mathrm{mg}$ of $1 \%$ lidocaine, $0.7 \mathrm{mg} \cdot \mathrm{kg}^{-1}$ of propofol, $0.2 \mathrm{mg} \cdot \mathrm{kg}^{-1}$ of atracurium, and $5 \mu \mathrm{g} . \mathrm{kg}^{-1}$ of fentanyl. Afterwards, $10 \mathrm{mg}$ of dexamethasone was administered IV and the patient was ventilated for 4 minutes with $100 \%$ oxygen via face mask in a $\mathrm{CO}_{2}$ absorber system. If 4 minutes after the administration of fentanyl BIS remained above $60,4 \%$ sevoflurane was administered via a face mask until the BIS reached 40 to 45 , at which time tracheal intubation under direct laryngoscopy was performed. Mechanical controlled ventilation was initiated and the respirator was adjusted to maintain $\mathrm{P}_{\mathrm{ET}} \mathrm{CO}_{2}$ between 30 and $35 \mathrm{mmHg}$.

Anesthesia maintenance was achieved with variable concentrations of sevoflurane, enough to maintain BIS between 40 and 45 . Supplemental doses of $0.1 \mu \mathrm{g} . \mathrm{kg}^{-1}$ of fentanyl were administered when SEF was above $15 \mathrm{~Hz}$.

Subsequent doses of $10 \mathrm{mg}$ of atracurium IV were administered to maintain TOF below $20 \%$ and the last dose was programmed to be administered approximately 30 minutes before the end of the procedure.

In order to normalize the $\mathrm{P}_{\mathrm{ET}} \mathrm{CO}_{2}$ and stimulate spontaneous ventilation, the tidal volume was reduced to $50 \%$ approximately 15 minutes before the end of the surgery, and 40 $\mathrm{mg}$ of parecoxib and $2 \mathrm{~g}$ of dypirone and distilled water $20 \mathrm{~mL}$ q.s.p. were administered at this moment.

Sevoflurane was discontinued at the end of the suture. At this moment, $0.2 \mathrm{mg}$ of flumazenil IV were administered to antagonize any residual effect of midazolam that might interfere with the evaluation of awakening (spontaneous eye opening).

If at the end of anesthesia the TOF were below $75 \%, 2$ $\mathrm{mg}$ of neostigmine associated with $1 \mathrm{mg}$ of atropine IV were administered. If after 3 minutes a complete reversion of the neuromuscular blockade was not observed, half of the dose of neostigmine and atropine was administered. The objective of this conduct was to reverse any residual effect of the neuromuscular blockade that might interfere in the evaluation of hand squeeze on verbal command.

After aspiration of the oropharynx, the patient was extubated when he/she presented effective spontaneous ventilation, which was defined by the maintenance of normal levels of tidal volume $(V T)$, respiratory rate $(\mathrm{RR}), \mathrm{SpO}_{2}$, and $\mathrm{P}_{\mathrm{ET}} \mathrm{CO}_{2}$ in room air.

Data for statistical analysis were collected at the following moments:

1. SBP, DBP, HR, SpO 2 , SEF, and BIS - before induction; 3 minutes after propofol; every minute after the beginning of sevoflurane until before intubation; 1 minute after intubation; every 15 minutes during anesthesia until immediately before extubation; and every minute (for 5 minutes) after extubation.

2. TOF - 3 minutes after propofol; before intubation; every $15 \mathrm{mi}-$ nutes during anesthesia; and before and after decurarization.

3. $\mathrm{P}_{\mathrm{ET}} \mathrm{CO}_{2}-1$ minute after intubation and every 15 minutes during anesthesia until immediately before extubation.

4. \% INSP and \% EXP - every minute after the onset of its administration until intubation; and every 15 minutes during anesthesia until immediately before extubation. 
5. After interruption of sevoflurane - time of awakening (spontaneous opening of the eyes); time to follow verbal commands (hand squeezing, every 2 minutes after spontaneous eye opening); time to achieve an Aldrete-Kroulik index equal or greater than 8 .

6. Every 15 minutes during the first 2 hours, in the post-anesthetic care unit (PACU) - SBP; DBP; $\mathrm{HR} ; \mathrm{SpO}_{2}$; pain severity evaluated by the visual analogue scale (VAS); and the incidence of postoperative nausea and vomiting (PONV). In cases of severe pain or frequent episodes of nausea or vomiting, $40 \mathrm{mg}$ of parecoxib or $4 \mathrm{mg}$ of ondansetron were administered IV respectively.

7. Changes in cardiac rhythm - recorded on the item "OBS", and the type of arrhythmia when it appeared, and treatment instituted should be recorded.

\section{Statistical analysis}

Initially all parameters were analyzed descriptively. For quantitative parameters this analysis was done through the observation of minimum and maximum values and calculation of means, standard deviation, and median. Absolute and relative frequencies were calculated for qualitative parameters.

The Student $t$ test was used to compare means of two groups and when the supposition of normalcy of the data was refused the non-parametric Mann-Whitney test was used ${ }^{8}$.

The Chi-square test was used to test the homogeneity among proportions ${ }^{8}$. To verify the behavior of the groups, considering the conditions of the study, Analysis of Variance for repeated measurements was used ${ }^{9}$. A level of significance of $5 \%$ was used for the tests.

\section{RESULTS}

The age of the patients ranged from 17 to 87 years (mean $49.21, S D \pm 18.13)$, of which 50 (78.1\%) were females.

Both groups were homogenous and did not show significant differences regarding demographic characteristics (Table I).

Table II shows the surgeries performed on 64 patients by group of vaporizer.

\section{Analysis of the data collected during the surgery}

During the surgery, the following parameters were observed: SBP, DBP, $\mathrm{SpO}_{2}$, BIS, TOF, $\mathrm{P}_{\mathrm{ET}} \mathrm{CO}_{2}$, \% INSP, \% EXP, and SEF.

For each of those parameters, the moments that best represented their evolution along the surgery were selected.

Analysis of Variance for repeated measurements demonstrated that vaporizers did not present significant differences in the means in the moments analyzed.

Therefore, both vaporizers had similar behavior during surgery for the following parameters: SBP $(p=0.813)$; DBP $(p=0.520) ; \mathrm{HR}(p=0.692) ; \mathrm{SpO}_{2}(p=0.720) ; \mathrm{BIS}(p=0.270)$; TOF during the procedure $(p=0.118)$ and before neostigmine $(p=0.327) ; P_{E T} C O_{2}$ during surgery $(p=0.620)$ and before neostigmine ( $p=0.330) ; \% \operatorname{INSP}(p=0.240) ; \% \operatorname{EXP}(p=0.188)$; and SEF $(p=0.439)$.

\section{Study of anesthesia regression}

The following periods of time were analyzed: between the beginning and end of the administration of sevoflurane; between the interruption of sevoflurane and spontaneous eye opening; between the interruption of sevoflurane and handgrip to verbal command (every 2 minutes after spontaneous eye opening); and from the interruption of sevoflurane until an Aldrete-Kroulik equal to or higher than 8 was achieved. Table III shows those times for both vaporizers.

On this table we can observe that vaporizers showed significant differences regarding the delta times between the interruption of sevoflurane and spontaneous eye opening, and between the interruption of sevoflurane and handgrip to verbal command.

Patients in the group of vaporizer II had significant higher values when compared to vaporizer $\mathrm{l}$.

Therefore, patients in the group of vaporizer II (Sevora$\mathrm{ne}^{\mathrm{TM}}$ ) had a mean time of spontaneous eye opening $34.5 \%$ greater and $29.5 \%$ greater for hand squeeze to verbal command when compared to vaporizer I (Generic Sevoflurane).

A significant difference was not observed between both groups regarding induction and interruption of sevoflurane,

Table I - Demographic Characteristics of the Patients According to the Group of Vaporizer (mean \pm SD)

\begin{tabular}{llll}
\hline & \multicolumn{2}{l}{ Vaporizer } & \\
\cline { 2 - 3 } Parameter & $\mathrm{II}$ & $\mathrm{p}$ \\
\hline Age (years) & $51.47 \pm 15.57$ & $46.87 \pm 20.44$ & $0.321^{(1)}$ \\
Weight $(\mathrm{kg})$ & $68.84 \pm 16.64$ & $65.66 \pm 11.69$ & $0.379^{(1)}$ \\
Height $(\mathrm{m})$ & $1.62 \pm 0.08$ & $1.64 \pm 0.07$ & $0.151^{(1)}$ \\
BMI (kg.m $\left.\mathrm{m}^{-2}\right)$ & $26.48 \pm 5.71$ & $24.31 \pm 3.59$ & $0.079^{(1)}$ \\
Gender (fem) & $28(87.5 \%)$ & $22(67.8 \%)$ & $0.070^{(2)}$ \\
\hline
\end{tabular}

Results expressed as Mean \pm Standard Deviation.

(1) Descriptive probability level of the Student $t$ test; (2) descriptive probability level of the Chi-square test.

Table II - Surgeries Performed According to Each Vaporizer

\begin{tabular}{lcc}
\hline \multirow{2}{*}{ Surgery } & \multicolumn{2}{c}{ Vaporizer } \\
\cline { 2 - 3 } & I & II \\
\hline Cholecystectomy & 14 & 11 \\
Hysterectomy & 05 & 05 \\
Nephrectomy & 00 & 03 \\
Colectomy & 01 & 00 \\
Plastic surgery of the abdomen & 03 & 01 \\
Thyroidectomy & 03 & 01 \\
Mammoplasty & 03 & 06 \\
Gastrectomy & 01 & 02 \\
Bilateral inguinal herniorrhaphy & 00 & 01 \\
Reconstruction of the intestinal transit & 01 & 00 \\
Correction of rectal prolapse & 01 & 00 \\
Cystoscopy + unblocking of the ureter & 00 & 01 \\
Oophoroplasty & 00 & 01 \\
Total & 32 & 32 \\
\hline
\end{tabular}


Table III - Delta of the Times Evaluated According to Vaporizer Groups

\begin{tabular}{|c|c|c|c|c|c|c|c|}
\hline Time between & $\mathrm{n}$ & Mean & $\mathrm{SD}( \pm)$ & Median & Minimum & Maximum & $\mathrm{p}^{*}$ \\
\hline \multicolumn{8}{|c|}{ Induction and interruption } \\
\hline Vaporizer II & 32 & 189.94 & 82.14 & 188.50 & 80 & 405 & 0.712 \\
\hline Vaporize I & 32 & 10.34 & 6.05 & 9.00 & 2 & 28 & \multirow[t]{2}{*}{0.011} \\
\hline Vaporizer II & 32 & 13.91 & 6.39 & 12.00 & 5 & 30 & \\
\hline \multicolumn{8}{|c|}{ Interruption and hangrip } \\
\hline \multicolumn{8}{|c|}{ Interruption and $\mathrm{A}-\mathrm{K} \geq 8$} \\
\hline Vaporizer I & 32 & 12.84 & 7.61 & 11.00 & 4 & 33 & \multirow[t]{2}{*}{0.059} \\
\hline Vaporizer II & 32 & 15.69 & 6.81 & 13.50 & 7 & 30 & \\
\hline
\end{tabular}

${ }^{*}$ ) Descriptive probability level of the non-parametric Mann-Whitney test. A-K: Aldrete-Kroulik.

and between the interruption of sevoflurane and the moment patients achieved an Aldrete-Kroulik index equal or above 8.

\section{Study of variables in the PACU}

During the period the patient remained in the PACU, the following parameters were observed: SBP, DBP, $\mathrm{HR}, \mathrm{SpO}_{2}$, and VAS.

Through Analysis of Variance for repeated measurements, a significant difference in the means at the moments of evaluation was not observed.

Therefore, both vaporizers had similar behavior in the PACU regarding the following parameters: SBP $(p=0.582)$, $\operatorname{DBP}(p=0.719)$, $\mathrm{HR}(p=0.358)$, and $\mathrm{SpO}_{2}(0.325)$.

\section{Study of the VAS}

The non-parametric Mann-Whitney test demonstrated that both groups of vaporizers did not show differences at the moments evaluated: $0 \min (p=0.120), 15 \min (p=0.058), 30$ $\min (p=0.054), 45 \min (p=0.100), 60 \min (p=0.582), 75 \mathrm{~min}$ $(p=0.458), 90 \mathrm{~min}(p=0.712), 105 \mathrm{~min}(p=0.428)$, and 120 $\min (p=0.279)$.

\section{Additional use of agents during the study}

In Table IV, additional drugs administered to patients in both groups of vaporizers are described.

Therefore, both groups of vaporizers did not show significant difference regarding the additional administration of drugs.

\section{DISCUSSION}

The monitoring used, especially BIS, SEF, TOF, ECG, HR, $\mathrm{SBP}, \mathrm{DBP}, \mathrm{P}_{\mathrm{ET}} \mathrm{CO}_{2}$, and $\mathrm{SpO}_{2}$ allowed the institution of an effective regimen of ventilation and the administration of adequate doses of sevoflurane, fentanyl, and atracurium to each patient regardless of the patient age and surgical procedure.

During the procedures, both agents showed similar behavior. However, after the interruption of the administration, a
Table IV - Absolute and Relative Frequencies of Additional Drug per Group of Vaporizer

\begin{tabular}{llll}
\hline & \multicolumn{2}{l}{ Vaporizer } & \\
\cline { 2 - 3 } & $\mathrm{I}$ & $\mathrm{II}$ & $\mathrm{p}^{*}$ \\
\hline Midazolam & $7(21.9 \%)$ & $4(12.5)$ & 0.320 \\
Fentanyl & $12(37.5 \%)$ & $14(43.8)$ & 0.611 \\
Atracurium & $7(21.9 \%)$ & $8(25.0 \%)$ & 0.768 \\
\hline
\end{tabular}

Results expressed in number of patients and percentages

$\left.{ }^{\star}{ }^{\star}\right)$ Descriptive probability level of the Chi-square test.

statistically significant difference was observed in the data regarding awakening from anesthesia. Patients in the Generic Sevoflurane group showed earlier spontaneous eye opening (3.57 $\mathrm{min}$ ) than those in the Sevorane ${ }^{\mathrm{TM}}$ group (means of 10.34 and $13.91 \mathrm{~min}$, respectively).

Similarly, a statistically significant difference in the time between the interruption of sevoflurane and hand squeeze on verbal command was observed. Patients in the Generic Sevoflurane group showed statistically lower means (3,5 $\mathrm{min}$ ) than those in the Sevorane ${ }^{\mathrm{TM}}$ group (means of $11.88 \mathrm{~min}$ and 15.38 min, respectively).

The differences in the times of "interruption of sevoflurane-spontaneous eye opening" and "interruption of sevoflurane-handgrip to verbal command" allow the conclusion that awakening was faster $(3.5 \mathrm{~min})$ in patients anesthetized with Generic Sevoflurane (Biochimico) than in those anesthetized with Sevorane ${ }^{\mathrm{TM}}$ (Abbott).

Despite those times having presented statistically significant differences, the values observed are within those mentioned by other studies ${ }^{10-12}$.

However, although awakening was statistically faster with Generic Sevoflurane, the anesthesiologists responsible for the cases, and who were not aware of which agent was administered did not observe and did not record at any moment of the study any difference in the clinical behavior of patients.

Although the agents used in this study are conditioned in vials with different characteristics and with different water contents, the statistical analysis of the data collected allows us to state that both Generic Sevoflurane (vaporizer I) and Sevorane ${ }^{\mathrm{TM}}$ (vaporizer II) had similar behavior in all moments and in all parameters recorded during the execution of anesthetic-surgical procedures. 
03. O'Neill B, Hafiz MA, DeBeer DAH - Corrosion of Penlon sevoflurane vaporisers. Anaesthesia, 2007;62:421.

04. Kharasch ED, Subbarao GN, Stephens DA et al. - Influence of sevoflurane formulation water conten on degradation to hydrogen fluoride in vaporizers. Anesthesiology, 2007;107:A1591.

05. Stephens DA, Kharasch ED, Cromack KR et al. - Sevoflurane vaporizers contain Lewis acid metal oxides that can potentially degrade sevoflurane. Anesthesiology, 2007;107:A1597.

06. Cromack KR, Kharasch ED, Stephens DA et al. - Influence of formulation water content on sevoflurane degradation in vitro by Lewis acids. Anesthesiology, 2007;107:A1593.

07. Grupa A, Ely J - Faulty sevoflurane vaporizer. Anesthesia, 2007; 62:412.

08. Rosner B - Fundamentals of Biostatistics, $2^{\text {nd }}$. Boston, PWS Publishers, 1986;584.

09. Timm NH - Multivariate Analysis with Applications in Educations and Psychology. Monterrey, CA, Brooks/Cole, 1975;687.

10. Malviya $\mathrm{S}$, Lerman $\mathrm{J}$ - The blood/gas solubilities of sevoflurane, isoflurane, halothane and serum constituent concentrations in neonates and adults. Anesthesiology, 1990;72:793-796.

11. Yasuda N, Targ AG, Eger EI II - Solubility of I-653, sevoflurane, isoflurane and halothane in human tissues. Anesth Analg, 1989;69:370-373.

12. Katoh $T$, Suguro $Y$, Nakajima $R$ et al. - Blood concentrations of sevoflurane and isoflurane on recovery from anesthesia. $\mathrm{Br} \mathrm{J}$ Anaesth, 1992;69:259-262.

Resumen: Portella AAV, Laurencel SM, Rosa DM, Rivera MIM, Quintero SO - Estudio Comparativo Doblemente Encubierto entre Sevoflurano Genérico y Sevorane®.

Justificativa y objetivos: El Sevoflurano se coloca en tres tipos de recipientes. Las diferencias de propiedades físico-químicas de esos productos se deben a los diversos procesos de fabricación, aunque sean esencialmente idénticos en cuanto a las pruebas de comparación química. Existe la hipótesis de que la molécula del Sevoflurano pueda presentar una inestabilidad química debido a la formación de ácidos Lewis, como consecuencia del material utilizado para la fabricación de los pomos y del contenido de agua.

El objetivo de este trabajo fue analizar la eficacia clínica del Sevoflurano cuando fue acondicionado en pomos diferentes.

Método: Se estudiaron 64 pacientes adultos distribuidos aleatoriamente en dos grupos. Fueron utilizados dos vaporizadores DatexOhmeda, siendo uno de ellos abastecido apenas con Sevoflurano Genérico y el otro con Sevorane®. El coordinador del estudio fue el responsable por el abastecimiento de los vaporizadores y no realizó la anestesia. En los dos grupos, se usó la misma técnica anestésica y la misma monitorización (ECG, $\mathrm{FC}, \mathrm{SpO}_{2}, \mathrm{P}_{\mathrm{ET}} \mathrm{CO}_{2}$, BIS, SEF, TOF, $\%$ INSP, \% EXP, PAS, PAD).

Resultados: No hubo diferencia entre los grupos durante la anestesia. Pero sí que hubo una diferencia estadística entre la interrupción del Sevoflurano y la abertura espontánea de los ojos $(13,91 \pm 6,39$ min Grupo II, y 10,34 \pm 6,05 min Grupo I), y la interrupción del Sevoflurano y el apretón de la mano al comando verbal $(15,38 \pm 6,47$ min Grupo II, y 11,88 $\pm 6,60$ min Grupo I). No hubo diferencia estadística entre la interrupción del Sevoflurano y el momento en que los pacientes alcanzaron el Índice de Aldrete-Kroulik igual o superior a 8.

\section{REFERÊNCIAS / REFERENCES}

01. Baker MT - Sevoflurane: are there differences in products? Anesth Analg, 2007; 104:1447-1451.

02. Kharasch ED - Sevoflurane: the challenges of safe formulation. APSF Newsletter, 2007;48:55.

Conclusiones: Durante la anestesia, no se registró diferencia entre los grupos. Aunque el despertar haya sido 3,5 minutos más rápido en el Grupo I (Sevoflurano Genérico), los anestesistas no se percataron de ninguna diferencia en el comportamiento clínico de los pacientes en cuanto a ese aspecto. 